\title{
Advancing Practice: How Can Emerging Models of Doctoral Study Help Support Architecture and Creative Practice?
}

\author{
SALLY STEWART \\ Mackintosh School of Architecture, The Glasgow School of Art
}

Can doctoral study provide practitioners with a valid approach to expanding their understanding of personal practice, and to deepen and future proof practice thinking and agency? This paper aims to explore the potential for doctoral education to develop research for practice, and consequently to support the very development of architectural practice itself.

The formal education of architects has tended to end with the completion of professional accredited programmes, and at the point of entry to the profession. While providing a springboard into practice, the resulting trajectory appears of limited range. While CPD remains essential, few architects return to the Academy to develop specialisms or to interrogate and develop their own creative practice in a more robust and rigorous way. While the length of the formal education and a lack of funding have been seen as barriers to postgraduate and doctoral study, research degrees have often been focused on technology, history and theory where research activities and outputs more comfortably connect to accepted academic research norms.

What can doctoral level study offer practicing architects, who see themselves first and foremost engaged in a creative activity? How can creative practice in its many guises be embraced as a legitimate and vital form of research? Can that research be at "zero distance" from the practice itself and provide new knowledge and understanding to support the sustained development to maturity and master.

The ADAPT-r network of seven European schools of Architecture, aims both to build research capacity for creative practice through developing research training consistent with practice, and in considering how networks and peer review can best serve practitioner researchers.

Initiatives such as the Scottish Graduate School for Arts and Humanities can provide insights from other disciplines as to how architectural research might form the basis for the shaping of future practice itself.

These projects point to the necessity to rethink how and where doctoral education and practice meet, particularly if our understanding of practice is to deepen and the range of disciplinary research necessary to support this is to be recognised.
If practice at its best is an activity that involves speculation, exploration, reflection and reflexivity how can architecture schools develop structures that better engage with this dynamic activity, and support mastery in practice and in the profession. What are the opportunities and challenges this presents for schools of architecture in attracting and supporting research for practice?

The paper will also consider how developing models such as PHD by design and by practice currently emerging in architecture schools, which may offer both the opportunity for practitioners to evidence their mastery of practice, and to advance the discussion of architecture as a discipline and creative industry.

\section{WHY PRACTICE?}

Having been involved in architectural education for over 25 years, I have taught at every level of architectural education, now working predominantly with postgraduate and research students. Recent experiences have prompted both the comparison of the demands and opportunities that architectural education these advanced levels provide and how this articulates with the professional experience beyond the academy.

It is widely accepted and expected that schools of architecture provide an education that is to a greater extent a preparation for entry to the profession, either through simulating practice within the design studio, providing live experiences of practice or through the systematic study of historical or contemporary precedents, behaviours and output. ${ }^{1}$ How then do research and doctoral programmes recognise practice?

This paper attempts to considers how practice led research can be encouraged to be a legitimate form of research and also to considered to consider what the obstacles are particularly at doctoral level to allow practice led/based research to come into its own.

Why is this important? Architectural practice and education have both changed dramatically over the last thirty years, responding to different drivers that arguably have resulted in more change than in the previous two centuries. The model of practice my generation was educated for no longer exists or at least in a highly altered form, while the approach I take to educating students now tries to 


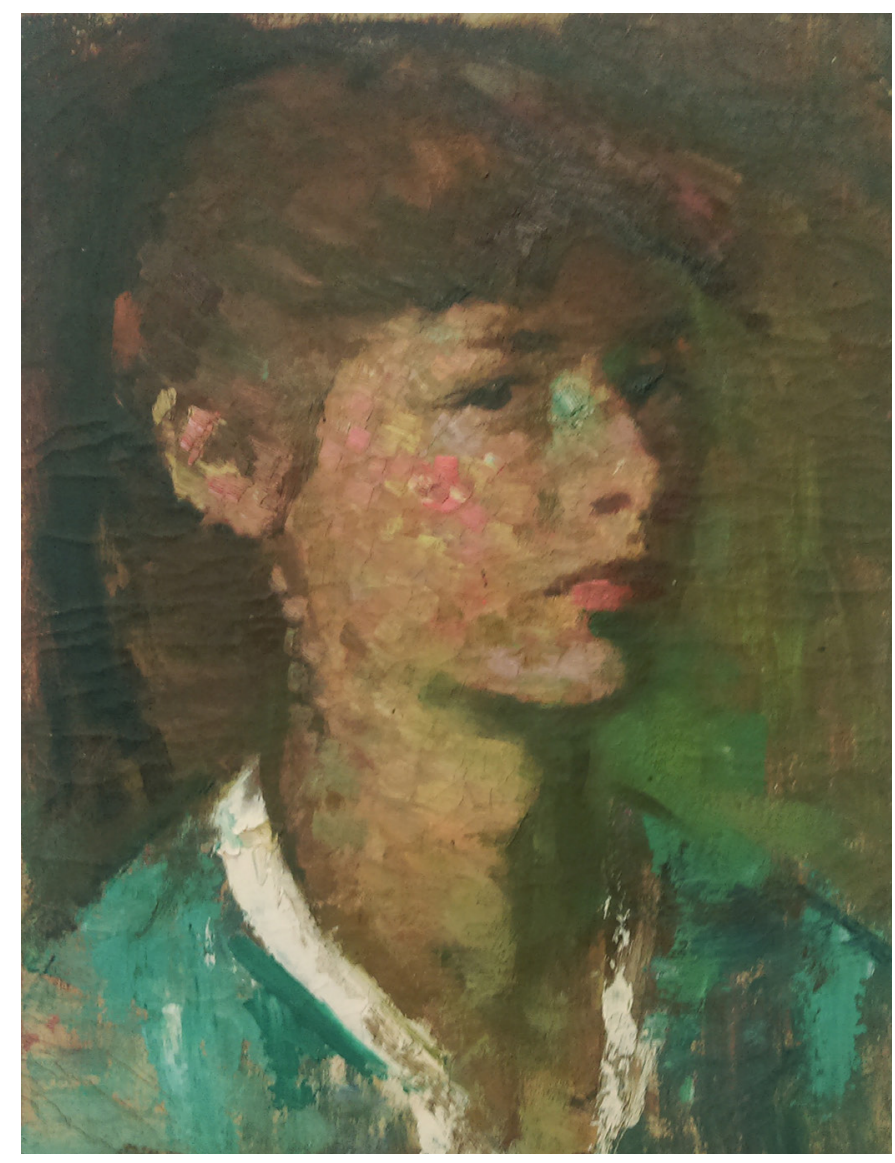

Figure 1: Self Portrait, Margaret Horner; portrait of the artist as a young woman, The Glasgow school of art, 1954

anticipate future practice as opposed to seeing the profession as a fixed and homogeneous entity. However, viewing the situation from the practice itself, as a discipline in flux, it requires research to be able to support, develop and also to challenge the forms and parameters of future practice. It requires research for practice, research led by practice.

What can doctoral study offer architects who see themselves operating first and foremost in architectural practice? Most architects do not necessarily identify the relevance of research or doctoral study to the development of practice. Why? Because research largely sits within the areas of history, theory or architectural technology, subjects (and methodologies) that in turn have shaped the form of the doctoral study, the doctoral thesis, the examination, the application, methodologies to a point where it appears to have little relevance to the approaches and methodologist of creative practice

Those who have trained as architects are conscious that architectural practice is a process involving speculation, experimentation and realisation, these aspects of the design act together in a complex Gordian knot, requiring both the tacit and explicit knowledge consolidating in a process that is part method part reflex.

This would appear to be key research territory if we expect practice and our understanding of how we practice/practise to evolve too.
However the prevailing model of doctoral study doesn't appear to align with that messy set of wicked circumstances that describe creative practice.

Along with others, I am interested in how architectural practice can be embraced as a legitimate and vital form of research. This involves challenging both the academic system to embrace practice led research (as an equivalent of more conventionally recognised forms of research) and also challenging the profession to think of doctoral level education as being a source of future practice development, an evolutionary engine.

\section{RESEARCH FOR PRACTICE}

One of the other things to be considered is the nature of research itself. One of the questions asked within GSA is what does a researcher look like; when does the work undertaken within an academic institution constitute research; how is it recorded and validated as such. We are not alone in asking these questions. With the audit of research is now a fixture within UK universities, ${ }^{1}$ tied to research income and esteem, so the question of what a researcher looks like is neither a glib one in the circumstances and neither is it an easy one within Architecture as a subject. It is unlikely that studio staff who are teaching design and developing research from that will have their research recognised due to the nature of the measures and metrics which form the basis of audits (which become the adopted metrics of the universities research committees). This at best omits, and worst ignores a significant proportion of potential research and biases against practice led research, as it doesn't respond to the normal means of measurement or fit into the conventional categorizations and so it is often discarded. Therefore you have to have sharper argument and work harder to be heard. ${ }^{3}$

In thinking about what a researcher looks like, I turn to a painting made by Margaret Horner, my aunt, in the final year of her degree at GSA in the 1950's. A painter looking both at themselves as a source of material and to an external personal practice developed through testing, experimentation and invention, establishing values, ambitions and a field of play. This is the basis of reflective practice, and what Glanville states "the element that turns the search into research". 4

The research I have done in the past has both related to my design practice, to designing for the elderly and for dementia and to developing and published design guides. I have published on the design work of others, and on work of my students in considering how the pedagogic aspects of our research and design activities have developed. While these were readily accepted as legitimate, they appear to be at some distance from practice itself. ${ }^{5}$

It is therefore difficult for our students to understand what we mean by research and our preoccupation with it. The definition of research appears to apply only to particular discrete pockets of activity they see and undertake everyday, but seldom to what they are regularly engaged with in studio, the most predominant aspect of their architectural education and subsequent professional careers. This prompts discussion how to make research that may 
Blind date

Robert Mantho,

Architecture tutor;

50 ish,

meets Sally Stewart,

deputy head, 40 ish
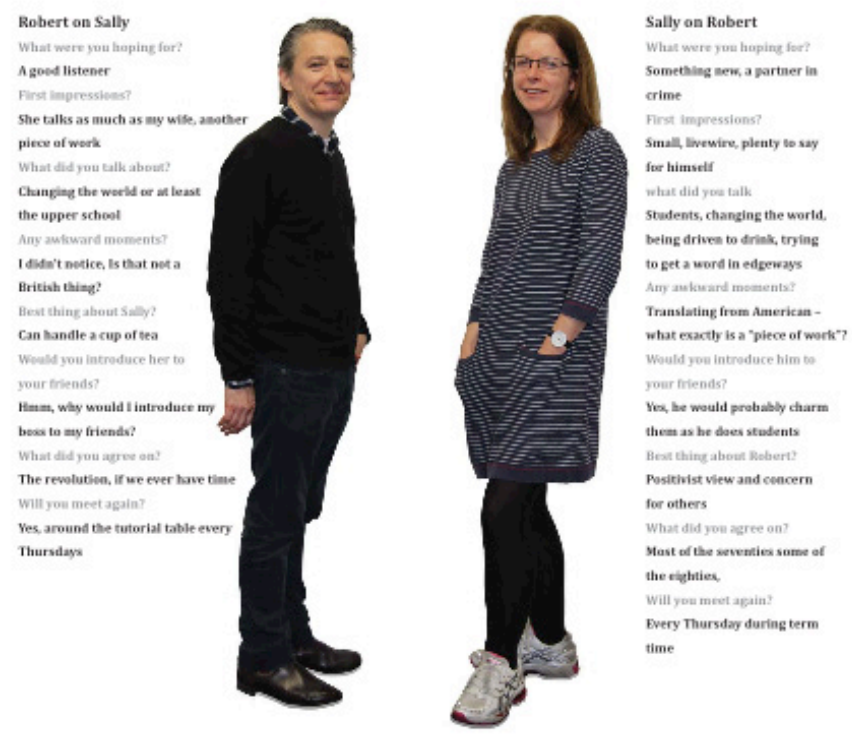

Figure 2: Identifying the circumstances of practice, the community of practice, Robert Mantho and the Author as an Academic Blind Date, 2014

have more relationship and relevance to studio and studio practice, and also to our fellow tutors who are practitioners. In this "designedly ways of knowing " acknowledging Nigel Cross, as a means to approach practice led research. ${ }^{6}$

Defining what might be meant as research is also important if we are to develop an understanding of what the obstacles to an acceptance of practice led research are.

David Yeomans notes that research "should in some way be advancing our knowledge or understanding of the field of design, as would research in any other field. Architecture is on weak ground here because it is not clear how either designs or built work do advance the practice of architecture". ${ }^{7}$

This is one of the difficulties many practitioners cite; they do not see the relevance to practice of much of the research they see happening within institutions. It may inform certain pockets, technological advance, urban theory, but it has little overall impact on advancing practice overall. So the situation is frustrated in both directions, much research is irrelevant, while practice based research is absent.

The question then may require to be phrased differently; how can practice be called research? What is it within the activity of designing that would allow it to become research? Brian Lawson talks about the "test being that it must move the field forward in some way", ${ }^{8}$ that practice itself is not research, that writing about that practice is a form of research of that practice but that in self does not more the practice forward.
So somehow we must develop some for of scientific method which recognising design activity such as problem solving, looking at patterns of behaviour and looking in a much more analytical way what we, think, say and do as we design.

Ranulph Glanville alerts us to the dangers of importing inappropriate research methodologies saying "We should not import approaches (and theories) unless we can show that they are appropriate to design. That they will not badly distort, that the insights that they will give us are both sympathetic and appropriate". ${ }^{9}$

Glanville points out that we must distinguish between research of design, research in design and research for design and to identify which of these we are interested in. ${ }^{10}$ By doing research he notes that we hope our design will become better, we hope it improves our performance ands allows us to act better, not to understand more; it is not merely about making knowledge but about telling us what we might do next, how to act.

\section{THE SCOTTISH CONTEXT AND BEYOND}

There are several ways that we have been looking at this in Scotland and within the Mackintosh School of Architecture. The first thing that has been very helpful in trying to get an overview of some of the obstacles has come with the establishing of what's called the Scottish Graduate School for Arts and Humanities (SGSAH)

SGSAH was created in 2014 with the aim of developing a more cohort, strategic and sustainable partnerships with organisations from across the creative, cultural and heritage sectors, and to provide access to research expertise across both universities and other organizations such as museums, archives and special collections. Funded through the Scottish Funding Council (SFC) and the Arts and Humanities Research Council, (AHRC), it considers itself to be the first national graduate school for arts and humanities. ${ }^{11}$ Its formation marks a shift both in the funding process for many doctoral awards ${ }^{12}$, but perhaps more significantly in the nature of the relationships across institutions and between higher education and other places of scholarly activity, and recognises the need to integrate and articulate strategy for the development of doctoral study and research capacity within the arts and humanities.

Similar initiatives such as research pooling, also encouraged and supported through the SFC, have resulted in the development of major 12 research interdisciplinary and multi-partner projects, and provided a means to develop research capacity in Scotland beyond the scope of any single institution. ${ }^{13}$ The SGSAH supports the development of research students and early career researchers in Scotland through a range of activities. ${ }^{14}$

The purpose of the SGSAH is not only to develop the cohorts of students funded through the AHRC, but to impact all postgraduate researchers across the SGSAH consortium, through the development of innovative and collaborative training provision that anticipates the needs of future practice rather than merely repeating what currently exists. This is perhaps the most challenging aspect for the consortium partners, and is dependent on the discussions occurring within and 
the intelligence coming the disciplinary panels. For architecture this means a dialogue with other visual and creative disciplines including creative writing, poetry, theatre and drama, film and television, fine art, design. This also presents the opportunity to better understand the nature and content of research proposals, research methodology and potential research collaborations being considered within other institutions and schools of architecture.

Why is that helpful? Through participation in the SGSAH selection process we start to be able to scan across creative disciplines and understand the forms that the most innovative research applications take. What has been very telling is looking across the creative disciplines, which includes art, design, literature and theatre, as well as

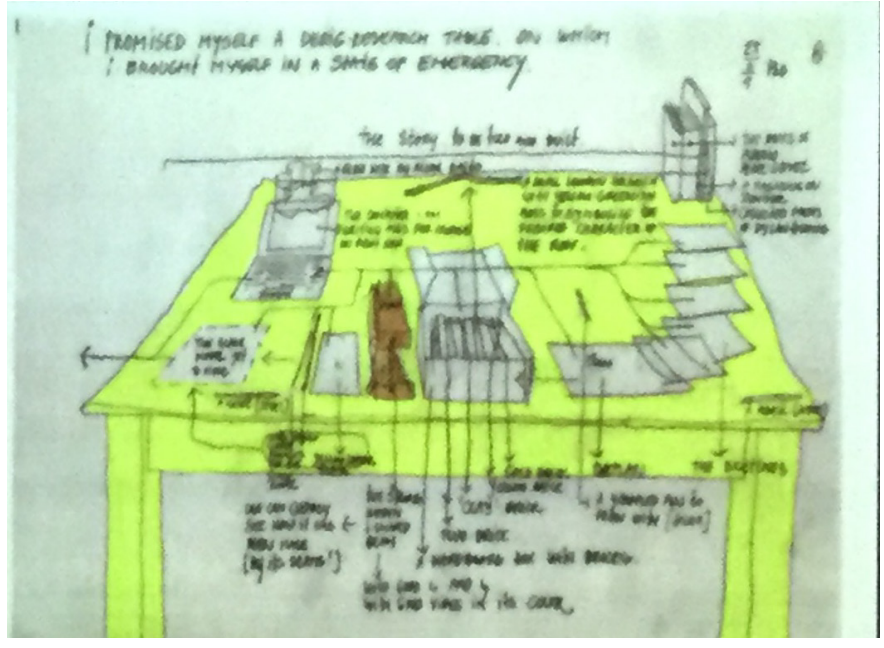

Figure 3: The location of practice, Jo Van Den Berghe. and the architects table 2014

architecture, that the architecture applications are perhaps the most conventional and orthodox. They are often limited in their ambition and subsequent success by repeating existing models of methodology or output, whereas within disciplines such as creative writing, paining and music applicants are very much led by how you might develop future practice, how the doctoral candidate is thinking about how their future practice might emerge from their research and the research be based in their emerging practice.

\section{ARCHIDOCT}

At a European level the Archidoct initiative, initiated through the EAAE ( European Association for Architectural Education) and ENHSA ( European Network of Heads of Schools of Architecture), has attempted to map the varied, divergent approaches to doctoral thinking in across European institution. ${ }^{15}$ In parallel, Archidoct ${ }^{16}$ also aims to consider how to counter isolation and promote the dissemination of the new knowledge created by these early career researchers by providing a publication where doctoral students could share research, seek comment and peer to peer learning. Working with online platforms and as a largely informal network this allows access to an expanding community across diverse subject matter within the discipline of architecture.

\section{ADAPT-R}

For the last four years MSA has been a partner in the ADAPT-r ITN, (Architecture, Design and Art Practice Training-research Initial Training Network) ${ }^{17}$ - a partnership between seven schools of architecture across Europe, which aims to provide doctoral training and early career research fellowships aimed at developing practice based research across architecture, design and fine art. The network, ${ }^{18}$ funded through the Marie Curie Actions FP7 initiative over four years, aims to build capacity in practice based research while also developing specialist research training suitable to and supportive of the nature of research in and of creative practice, developed and tested through 33 early career research fellows and 7 experienced researchers. ${ }^{19}$

At the heart of the network is a programme of six monthly Practice Research Symposium, allowing a regular shared research training programme to be established, while giving doctoral candidates the opportunity to share research work in progress. ${ }^{20}$ By its completion in December 2016, ADAPT-r will have resulted in two major research conferences, a major exhibition, ten research publications, and a resource portal for supervisors involved in the development of practice based doctoral work.

The practice led research is conducted by early career research fellows (ECRs) with a track record of innovative practice, who are able to use the income from the fellowship to release time from their practice to study its outputs, behaviours and methods to provide the basis for research into venturous practice. The aim is for practitioners to undertake research into their own work at zero distance from the work, while embedded in practice and to then disseminate that research to others. The project also has a team of experienced researchers, one working in each of the institutions, who over the four years have captured the knowledge generated within the project. By the conclusion of the project there will also be 10 PHD's completed by ECRs, providing an insight into the diversity within practice and the potential of doctoral study to develop insights into personal creative practice.

The ERs and ERSs come from across Europe, a condition of funding being that fellows must be hosted in an institution in different country to their normal domicile. While this is not an issue for the experienced researchers, for the ECR's embedded in practice this initially seemed problematic. One of the key issues for architects is that the majority of practice are located or anchored in relation to their work base, and the resulting work responds to that location. ${ }^{21}$

Fellows hosted at MSA have ranged across the creative disciplines including architecture, landscape design and painting. Their period as fellows has revealed some of the challenges facing practitioners in engaging with sustained reflective research while remaining in practice; the difficulties and opportunities that mobility requirements within grants demand; reflexivity and working at zero distance from the research subject, framing research in the context of the small or medium enterprise. 
Many of the ESRs have found that careful navigation of the use of their time between practice location and host institution has provided the opportunity to step out of the practice at regular intervals to provide the space and thinking time to reflect back and to develop the research thinking form that. This also build in a momentum supported both by the PHD and fellowship supervisory team, and ensures that research thinking, methods and output is being developed rather than merely further consultancy generated. ${ }^{22}$ Time therefore is a significant lever that allows the research to happen, and doctoral study to become a reality, and one that will contribute to the future of the practice.

The process then requires self-reflection, with its attendant possibilities and sensitivities. Jo Van Den Berghe, a Belgian architect and teacher describes how he consciously began the research (into himself) through drawing the place where he saw the research would occur ( his work table and drawing board) and the tools he would be using (pens, favourite pencil, models etc).

This immediately establishes the research as particular to him, about him and reliant on his actions, with the research questions also stemming from his portfolio of projects. This is a core difference in this approach to developing a PHD thesis; one that allows the key research

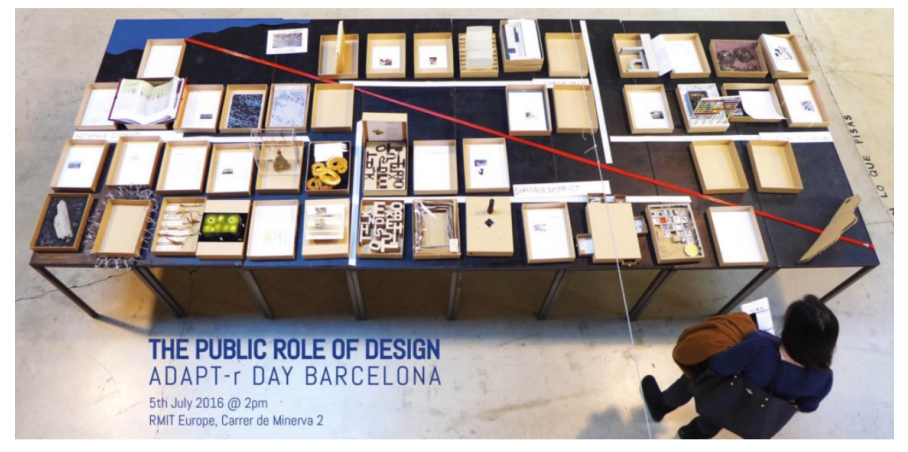

Figure 4: ADAPT-r events provide a focus for research training and dissemination.

questions to emerge rather than be imposed from the beginning, the research activity is not an alien but generated though familiar actions and activities such as means of dissemination through drawings, describing and presenting work to others.

Within the ADAPT-r system a critical element is the sixth monthly Practice research symposium meeting, where all candidates presenting work to other in an open forum. This is crucial not only to allow critique of progress but also to be able to share insights across the cohort. Research training also become discussions of emerging established and emerging methodologies rather than compliance events.

This element of this model of doctoral study is the most divergent from the conventional process, where the work is generated by an isolated researcher and discussed with a relatively limited number of people. Within the ADAPT-r model candidates regularly present to twenty people, including a panel of supervisors and changing critics, while having the opportunity to review other presentations from over forty peers. This demands the candidate can present a range of audiences, those conversant with their research, those who are seeing it for the first time, candidates at the beginning and also at the end of their PHD trajectory. This provides a collegiate forum for criticism, but it is also one that we recognise from architectural education and practice, one that is appropriate and stems from our own practice signature.

This model provides a series of methodological steps including; identifying key triggers within their practice, considering case studies and where the practice has emerged from, identifying urges and preoccupations, tracing communities of practice and considering creative output. These are not necessarily sequential, and research across the ADAPT-r fellow reveals a variety of ways fellow use and reuse these to generate insights specific to their own mind space and situation.

It is important that we also describe the value this process to others beyond the network. PRS weekends are open to anyone, and a range of regular ADAPT-r days hosted by the partner institutions also allow the emerging research to be disseminating to the wider professional and academic community.

The PhD presentations and examinations are also open events, with the candidates presentation and examiners comments captured on video and forming part of the durable record of the doctorate. These can then be shared to provide a searchable database, an additional contribution to the development of doctoral research. Attending the examinations is a critical element of the research training - but one largely absent from most conventional PHD systems. Vivas often have a performative element within them, locating and engaging the audience at close proximity with the work, emerging them in the practice context, sparking insights through the subsequent discussion, access to the exhibition materials and thesis

During the project we have built up a body of PHD completions, through fellows and associated candidates, and this allows us to use these as a means to demonstrate the distinctiveness of practitioners and the resulting doctorates. This is not merely an albeit different but formulaic process that allows one type of architect and creative practitioner to undertake doctoral study. Events such as the "Belgian Nine" allowed the completed PHD candidates to describe the experience they had had, how it had tested them, the insights the PHD generated and how that has impacted their future now current practice. Many indicated the sense of exposure they encountered, how they we're opened to doubt, the explicit and tacit elements of their day to day work they were able to examine afresh or for the first time.

Arnaud Hendrickx described the second year of the process as akin to looking for the Loch Ness monster, a mythic phase and the accompanying uncertainty as to whether the goal would ever be achieved. He also noted that this was the only way of undertaking doctoral study that had any relevance to him and his practice. 


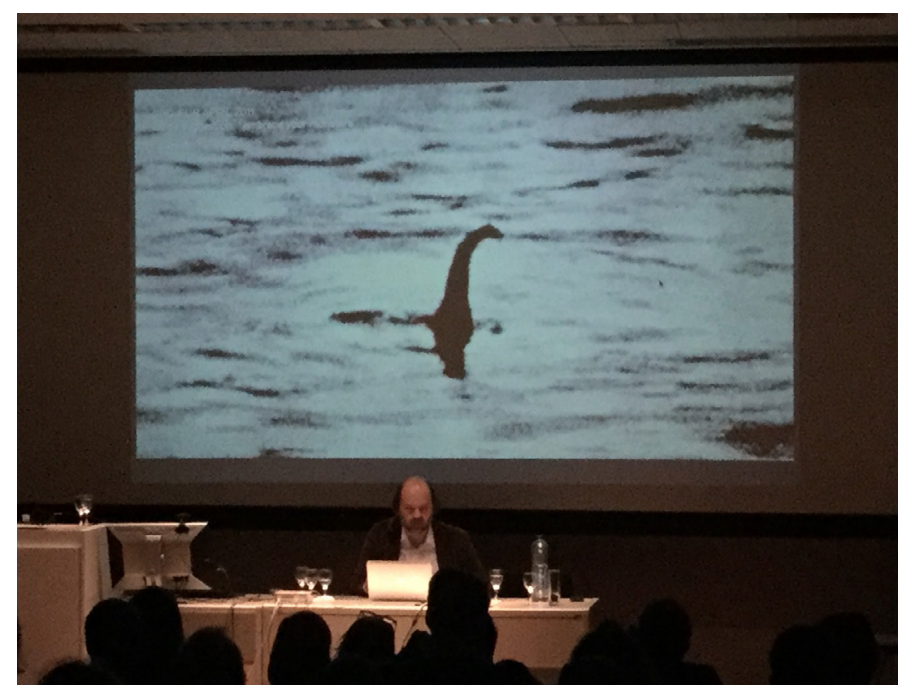

Figure 5: Arnaud Hendrickx reflecting on the challenges and uncertainties of doctoral study during presentations by the Belgian 9, Ghent April 2016

\section{CONCLUSION}

For MSA, participation in ADAPT-r and the SGSAH consortia have provided insights into the parallel or alternative doctoral programmes at other institutions in the UK or across Europe, as well as helping to challenge the obstacles in developing the creative practice research.

Inevitably the model we pursue will evolve, nuanced by our own local and national circumstances, and in response to the architectural profession with whom we wish to provoke, support and influence.

However as the first marks are made on the map the territory begins to be charted and the objective of doctoral study advancing practice becomes a possibility,

\section{ENDNOTES}

1 Ranulph Glanville describes notes "It is about the Practice of Practice (or practising practising" which highlight how self conscious we become when we consider what we do do. Ranulph Glanville, An irregular dodecahedron and a lemon yellow Citroen, 2003, in Van Schaik, I.

2 The results of the most recent Research Excellence Framework can be found at http://www.ref.ac.uk/ accessed 20 July 2016. It is difficult to gain a comprehensive overview of the performance of architecture schools as the discipline can be returned under a range of subject groups from art and design, history of art through to built environment

3. Dean and Smith noted "Terms such as practice based research have been developed by creative practitioners, partly for political purposes within higher education, research and other environments to explain justify, and to argue as forcefully as possible in an often unreceptive environment - that they are important to the generation of knowledge as other more theoretically, critically or empirically based research methods", Smith, Hazel and Dean, Roger ed. Practice led research, research led practice in the creative arts 2009, Edinburgh University Press.

4. Glanville, Ranulph, in Design Prepositions, 2007, The Unthinkable Doctorate, Sint Lucas Acacademie, Joost, Gesche, Bredies, Katharina, Christensen, Michelle, Conradi, Florain, Unteidig Andreas eds

5. I have been research active for 16 years and have been included in three Research Assessment Excercises, but I have found that limiting in that it has tended to driven the direction of my research rather than allowing me to consider what research I would wish to undertake.

6. Cross, Nigel (1982). Designerly ways of knowing. Design Studies, 3(4) pp. 221-227.

7. Yeomans, David, Can design be called Research?, Architectural Research Quarterly, vol1, autumn 1995

8. Lawson, Bryan, 2002. The subject that won't go away But perhaps we are ahead of the game. Design as research. Architectural Research Quarterly, 6, pp 109-114
9. Glanville, Ranulph, in Design Prepositions, 2007

10. Both Lawson and Glanville warn against the assumption that practice itself is research. Lawson candidly states that "not only is some design not very good, but much design does little to distinguish itself as having contributed knowledge beyond solving the local problem." However he goes on to note that "there are many indicators that can be used as a first step in detecting design of research quality". Lawson, Bryan, 2002. The subject that won't go away But perhaps we are ahead of the game. Design as research.

11. http://www.sgsah.ac.uk/about accessed 20 July 2016

12. SGSAH PHD studentships cover all aspects of the arts and humanities and include literature, languages, theology but also created practice. 54 fully funded studentships are offered annually through an open competition.

13 Swedish architecture schools benefitted from a similar collective approach to government research funding which resulted in the founding of Sweden's Schools of Architecture research initiative (SSA) in 2011 and ReseArch the following year. http:// www.arch.umu.se/en/research/research-environment-in-sweden/ accessed 20 July 2016

14 SGSAH is based upon the AHRC Doctoral Training Partnership Scotland, a prestigious consortium of eight Higher Education Institutions The AHRCDTP Scotland supports doctoral research and training in a wide range of Arts and Humanities disciplines, and provides access doctoral funding, currently through awarding 54 fully funded doctoral student scholarships per annum. Applications are considered by four specialist disciplinary panels, and then ranked identifying those with the strongest combination of research proposal, supervision expertise and research profile.

15 Their overview gathers perspectives from 18 countries and educational systems across the European Union, in Voyatzaki, Maria, ed. Doctoral Education in Schools of Architecture across Europe, 2014 ENHSA, ISBN 978-960-9502-15-3

16 Archidoct, e journal for the dissemination of doctoral research in architecture, http:// www.enhsa.net/archidoct/about.html, accessed 20 July 2016

17 www.adapt-r.eu

18 The ADAPT-r project is the largest of its kind within the European Union's Seventh Framework Programme FP7/2007-2013FP7, but unique in focusing on practice led research. http://cordis.europa.eu/project/rcn/106609_en.html accessed 20 July 2016

19 ADAPT-r consortium partners are KULeuven Faculty of Architecture, RMIT Europe, University of Westminster School of Architecture and the Built Environment, University of Ljubljana Faculty of Architecture, Estonian Academu of the Arts Faculty of Architecture, Aarhus School of Architectuture, The Glasgow School of Art Mackintosh School of Architecture

19 ADAPT-r consortium partners are KULeuven Faculty of Architecture, RMIT Europe, University of Westminster School of Architecture and the Built Environment, University of Ljubljana Faculty of Architecture, Estonian Academu of the Arts Faculty of Architecture, Aarhus School of Architectuture, The Glasgow School of Art Mackintosh School of Architecture

20 ADAPT-r builds on the invitational PHD model developed by Leon van Schaik at RMIT over a thirty year period with Ranulph Glanville and Sand Helsel. See Leon van Schaik and Anna Johnson, The Pink Book, By Practice by Invitation Design Practice Research 1986-2011, ISBN 9780987210814

21 Described by Richard Blythe, Professor of Architecture and Dean, Architecture and Desig RMIT as their terroir, the title of his PHD by practice, and the basis for the naming of his own design practice located in Tasmania, see Blythe, R 2008, A terroir of terroir (or, a brief history of design-places), Doctor of Philosophy (PhD), Architecture and Design, RMIT University.

22 see note 10 